\title{
Reward without Dopamine
}

\author{
Claire Matson Cannon and Richard D. Palmiter \\ Department of Biochemistry and Howard Hughes Medical Institute, University of Washington, Seattle, Washington 98195-7370
}

Dopamine (DA) is believed to play a fundamental role in reward processes. Virtually all drugs of abuse activate dopaminergic systems, as do "natural" rewards such as sexual interaction and food. Sweet-tasting solutions, for example, are a well characterized natural reward. In the present experiments, we used mice that cannot make DA (DD mice) to test the hypothesis that DA is necessary for reward. Sucrose preference, assessed with a computerized "lickometer," was used to determine whether DD mice respond preferentially for rewarding stimuli. DD mice preferentially chose sucrose over water, and also preferred the noncaloric sweetener saccharin. Furthermore, the rate of licking, bout size, and length were greater in DD mice drinking sweets than in controls. These data refute the necessity of DA for the reward processes manifested by sucrose preference. However, DD mice initiated licking less frequently than control mice and had fewer total licks. We suggest that DD mice have a deficit of goal-directed behavior that is not specific to reward processes. Lastly, juvenile DD mice demonstrate robust sucrose preference before experience with food in the presence of DA. Thus, DA is not required for mice to learn to consume sweet solutions preferentially. We conclude that DA is not required to find the sweet tastes of sucrose or saccharin rewarding.

Key words: knock-out mice; tyrosine hydroxylase; motivation; striatum; ingestive behavior; sucrose preference

\section{Introduction}

Virtually all drugs of abuse elicit the activation of dopaminergic systems, as do "natural" rewards such as sweets (Smith, 1995; Berridge and Robinson, 1998; Robinson and Berridge, 2000; Nestler, 2002; Schultz, 2002; Wise, 2002; Salamone et al., 2003). In the present study, we test the hypothesis that dopamine (DA) is necessary for reward processes by using mice that cannot make DA (DD mice) (Zhou and Palmiter, 1995). DD mice are less active than normal mice and demonstrate minimal spontaneous feeding behavior (Zhou and Palmiter, 1995; Szczypka et al., 1999). Complex behaviors such as bar pressing, maze running, and conditioned place preference can be used to make inferences about reward (Laakso et al., 2002). However, these tasks require multiple neural events in addition to reward processes, (e.g., sensory perception, motor ability, learning, and memory) that can be confounding. Furthermore, the hypoactive DD mice are less likely to perform complex behavioral tasks. To evaluate the reward processes of DD mice while avoiding many of these problems we have used a simple preference test for a well established natural reward, sucrose. Reward processes elicited by sucrose correlate with the activation of dopaminergic neurons and the release of DA (Hernandez and Hoebel, 1988; Hajnal and Norgren, 2001, 2002), and DA receptor antagonists or lesions of dopaminergic neurons can reduce the consumption of sucrose (Smith, 1995; Pecina et al., 1997). Sucrose preference is a widely used index of reward, and the operant behavior, licking, is a sen-

Received July 29, 2003; revised Sept. 3, 2003; accepted Sept. 3, 2003.

This work was supported by National Institutes of Health Training Grant 5 T32 NS 07332 (C.M.C.). We thank Mustafa Bseikriand Christopher Scannell for assistance with these studies, Michelle Brot for help with the lickometer cages, members of the Palmiter laboratory for comments on this manuscript, and Kristen Nagata and Nora Meneses for maintenance of the mouse colony.

Correspondence should be addressed to Dr. Claire Matson Cannon, Department of Biochemistry, University of Washington, Box 357370, Seattle WA 98195-7370. E-mail: caesia@u.washington.edu.

Copyright $\odot 2003$ Society for Neuroscience $\quad$ 0270-6474/03/2310827-05\$15.00/0 sitive measure suitable to animals with lower spontaneous activity. Lastly, solutions of sucrose elicit hedonic responses in newborn human infants (Steiner, 1973) and in 3-d-old rat pups (Hall and Bryan, 1980), suggesting that the reward value of sucrose is established early in life and that the sucrose preference test requires minimal learning and memory.

\section{Materials and Methods}

All experiments were conducted in accordance with the guidelines of the Institutional Animal Care and Use Committee at the University of Washington. Mice were housed in a temperature- and humidity-controlled room with a $12 \mathrm{hr}$ light/dark cycle. Mice were fed a pelleted, higherenergy (25\% fat) breeder diet (5LJ5; PMI Nutritional Inc., Brentwood, $\mathrm{MO}$ ) in the birth cage, and a liquid rodent diet (LD-101; Test Diet, Richmond, IN) in the lickometer cages. Adult mice were housed individually in the lickometer cages for the duration of the experiment.

$\mathrm{DD}$ and wild-type mice. Mice lacking tyrosine hydroxylase $(\mathrm{TH})$, in dopaminergic neurons (DD or $T h^{-1-} ; D b h^{T h /+}$ ) were bred as described and maintained on a mixed C57BL/ $6 \times 129 / \mathrm{SvEv}$ genetic background (Zhou and Palmiter, 1995). Littermate controls, referred to as wild type (WT), had at least one intact Th and one intact Dbh allele, which are sufficient for the production of nearly normal levels of DA and norepinephrine (Thomas et al., 1998; Rios et al., 1999). At birth, DD mice resemble WT mice, but by 2 weeks they are runted, hypoactive, and hypophagic; they will starve in the midst of readily available, palatable foods (Zhou and Palmiter, 1995). From the onset of this phenotype, DD mice were injected daily with L-3,4-dihydroxyphenylalanine (L-dopa) $(50 \mathrm{mg} / \mathrm{kg}$, i.p.), a dopamine precursor. L-Dopa injection elicits intense hyperactivity and voracious feeding by DD mice, but there is no such effect in WT mice. Within $12 \mathrm{hr}$ after the administration of L-dopa, DD mice return to their basal hypoactive and hypophagic state; by $18 \mathrm{hr}$ DA levels are $\sim 1 \%$ of normal.

Lickometer cages. Lickometer cages (Columbus Instruments, Columbus, $\mathrm{OH}$ ) were modified for mice; the drinking spouts were $5 \mathrm{~cm}$ apart, and were inserted $2 \mathrm{~cm}$ above the metal wire cage floor (see Fig. $1 \mathrm{~A}$ ). The cage was placed on a heat source so that the cage temperature was $\sim 26^{\circ} \mathrm{C}$. The program Event Counter (Columbus Instruments) cumulated events 
in 10 -sec intervals. An event was recorded when the mouse came in contact with the floor of the cage and the metal spout at the same time, usually while licking but occasionally by touching the spout with a paw. However, these non-lick events were easily detected because rodents lick in rapid bursts (Davis and Smith, 1988; Davis, 1998). Our mice lick at a rate of 20-80 licks per $10 \mathrm{sec}$ interval. Therefore, we excluded tests during which the total number of events, recorded at either tube during $5 \mathrm{hr}$, was $<10$. We further modified the lickometer cages for juvenile mice by raising the floor so that the spout was elevated only $1 \mathrm{~cm}$, rather than 2 $\mathrm{cm}$. The internal temperature was raised to $\sim 30^{\circ} \mathrm{C}$, and to increase humidity we placed a wet towel beneath the wire cage floor and another heat source on the cage top. Two $1 \mathrm{~cm}$ diameter holes in the cage provided ventilation.

Preference tests. In the first experiment, each test began $18 \mathrm{hr}$ after the last treatment with L-dopa and lasted for $5 \mathrm{hr}$ (10:30 A.M. to 4:30 P.M.). On the first $4 \mathrm{~d}$, adult DD and WT mice were given water in both tubes, then for $5 \mathrm{~d}$ they were given the choice of water or a $0.5 \mathrm{M}$ sucrose solution. In the next experiment, adult mice were given two doses of amphetamine (AMPH) $(2 \mathrm{mg} / \mathrm{kg}$, i.p. $)$ at 24 and $26 \mathrm{hr}$ after the last treatment with L-dopa. Two hours after the last injection of AMPH ( $28 \mathrm{hr}$ after L-dopa), mice were given access to water and either $0.5 \mathrm{M}$ sucrose or $10 \mathrm{~mm}$ saccharin, a noncaloric sweetener (Bachmanov et al., 2001; Smith and Sclafani, 2002) for $15 \mathrm{hr}$. In the final experiment, DD mice were identified at postnatal days 14-17, and were removed from the home cage with a control littermate. Juveniles were tested individually overnight on 2-3 consecutive nights in modified lickometer cages, but spent the days together with a surrogate dam. The number of licks was used to calculate a preference score. The preference for the sweet solution was calculated by dividing the number of licks at the sweet tube by the total licks at both tubes. A score of 0.5 indicates no preference for either spout, whereas $>0.5$ indicates a preference for sweet. The position of the water and the sweet tubes were randomly assigned, then switched on subsequent days. Sucrose and saccharin (Sigma Aldrich, St. Louis, MO) were diluted in the same sterile water the mice were accustomed to drinking. Mice did not have access to a pellet or a liquid diet during the preference tests.

Statistical analysis. Data were analyzed by Student's $t$ test with significance set at $p<0.05$. Preference scores were compared with 0.5 (no preference). Values are means \pm SEM.

\section{Results}

Mice lacking DA demonstrate normal sucrose preference despite diminished ingestive behavior

When water only was available, all WT mice licked at both tubes during each of the $5 \mathrm{hr}$ tests (mean total licks per test, $134 \pm 75$ ). As predicted by their hypophagia and hypoactivity, the licking behavior of DD mice was less than that of WT mice. From a total of 12 DD mice, 3 did not lick during any test and were excluded from analysis, whereas the remaining DD mice licked, on average, during only 1.6 of the 4 tests (mean total licks per included test, $30 \pm 10)$. DD and WT mice had no significant preference for either tube position when both tubes contained water (data not shown). On the next 5 test days, water and sucrose were available. Of 12 DD mice, 4 did not lick during any test, and the remaining 8 mice licked, on average, during only two of the five tests. For preference analysis, we included only the DD mice that drank during both position (water only) and sucrose-preference tests $(n=8)$. Both WT and DD mice had a significant preference for sucrose (Fig. $1 B$ ). Furthermore, both DD and WT mice responded to sucrose with increased licking (total licks at either spout by WT mice, $364 \pm 68$; by DD mice, $127 \pm 47$ ). Thus, both WT and DD mice preferentially chose sucrose over water and increased their total intake when sucrose was available. This result is in contrast with a previous report wherein DD mice had no sucrose preference as measured by volume intake (Szczypka et al., 2001). However, the lickometer system used here is more sensi-
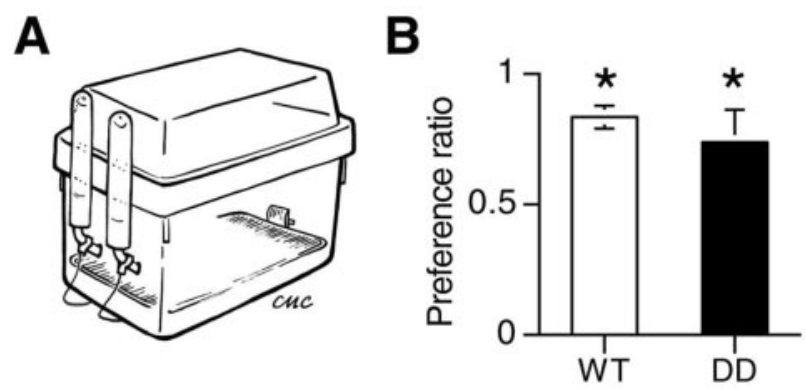

Figure 1. Preference for $0.5 \mathrm{~m}$ sucrose by WT and DD mice. $A$, Lickometer cage modified for mice. $B, W T$ and DD mice were given the choice of either water or sucrose. Both WT $(n=3)$ and $\mathrm{DD}(n=8)$ mice demonstrated significant preference. Asterisks denote preference $(p<0.01)$.

tive, has a diminished margin of error, and allowed us to exclude mice that had no drinking behavior, which otherwise receive an erroneous preference score of 0.5 (or no preference).

\section{Amphetamine eliminates residual dopamine in DD mice}

In DD mice, DA levels were $\sim 1 \%$ of normal at the start of the $5 \mathrm{hr}$ test. In the next experiment, we eliminated residual DA by treating mice with AMPH, which releases monoamines from neurons and prevents their reuptake, thereby flooding the synapse with transmitter (Sulzer et al., 1995). One of the behavioral correlates of AMPH treatment is hyperactivity. When DD mice were given AMPH 24 hr after L-dopa, they were modestly hyperactive, suggesting that release of monoamines, including residual DA, can activate the hypersensitive neural circuits of DD mice (Kim et al., 2000) required for locomotion (Fig. $2 A, C$ ). In WT mice, a second dose of AMPH $2 \mathrm{hr}$ later resulted in a second bout of locomotion (Fig. $2 B, C$ ), whereas DD mice had no response to the second dose of AMPH (Fig. 2A,C), in agreement with previous results (Szczypka et al., 1999; Heusner et al., 2003). A third injection of AMPH given $42 \mathrm{hr}$ after L-dopa also elicited no response (Fig. $2 A, C)$. These results suggest that in the absence of TH, DD mice do not retain residual DA after AMPH treatment.

\section{Mice lacking dopamine demonstrate robust sucrose preference after amphetamine pretreatment}

Although DD mice are generally hypoactive, their locomotor activity is comparable with that of WT controls for several hours beginning $\sim 30 \mathrm{hr}$ after L-dopa injection. This activity is not DAdependent, because it is unaffected by previous treatment with AMPH or DA receptor blockers (Szczypka et al., 1999). During this period, DD mice explore the lickometer cages, rear, and attempt to climb the walls, similar to WT mice (Fig. 2A). Thus, for subsequent studies we prepared DD mice by injecting AMPH at 24 and $26 \mathrm{hr}$ after L-dopa and beginning the 15-hr preference test at $28 \mathrm{hr}$, just before lights out. In contrast with the $5 \mathrm{hr}$ tests (Fig. 1), all DD mice demonstrated some licking behavior during each $15 \mathrm{hr}$ trial. This difference may reflect the longer duration of the test, most of which was in the dark cycle, and the inclusion of the period of spontaneous locomotor activity. Previous treatment with AMPH did not affect the total number of licks (consumption) by either WT or DD mice (Fig. 2D).

As in the previous experiment, the DD mice had a preference for sucrose that appeared identical to that of WT mice (Fig. $3 A$ ). The pattern of feeding by DD and WT mice was markedly different, as illustrated by the representative examples (Fig. 3G,H); WT mice initiated licking many times throughout the night (Fig. 3B), whereas DD mice had fewer (Fig. 3B), longer bursts of more rapid licking (Fig. 3D,E), and a greater number of licks per bout (Fig. 
A

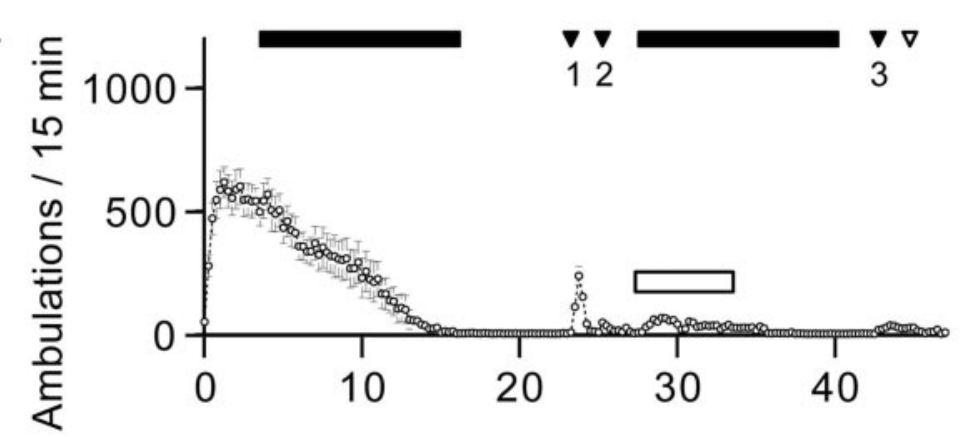

B

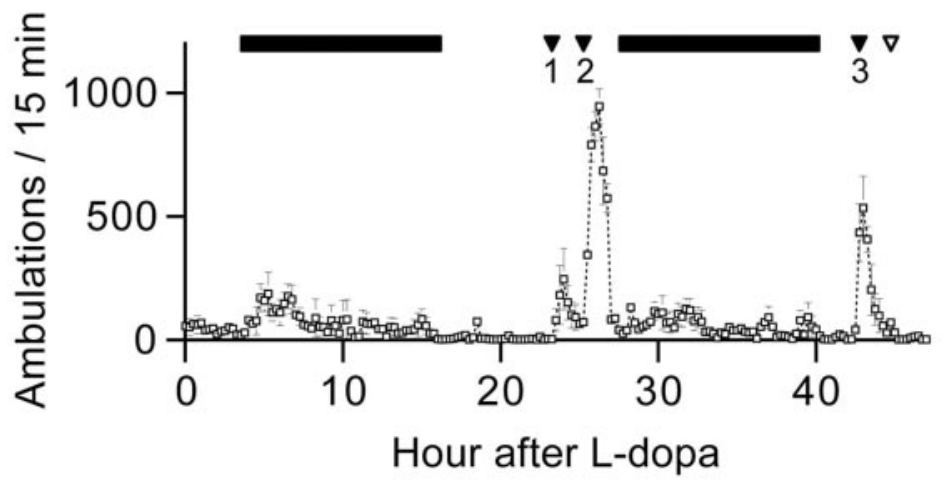

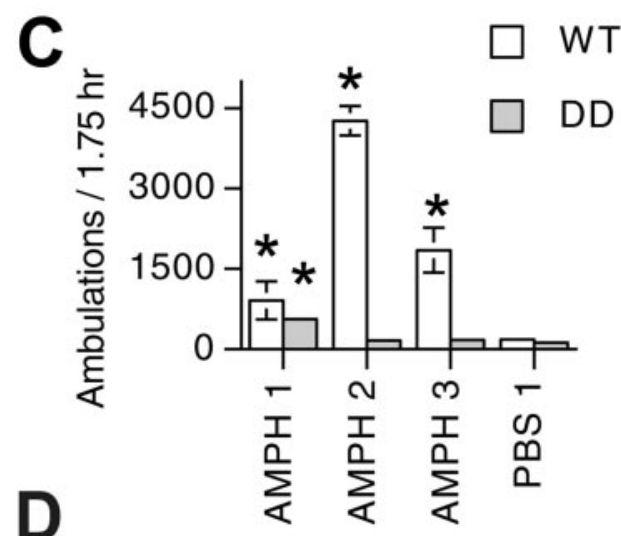

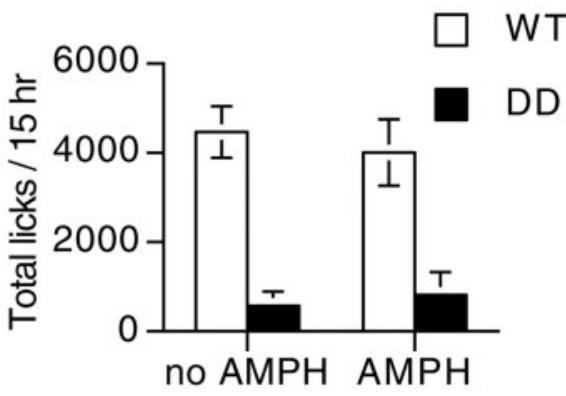

Figure 2. DD mice did not increase locomotor behavior in response to repeated AMPH. A, DD mice $(n=12)$ were given L-dopa $(50 \mathrm{mg} / \mathrm{kg})$ at time $0, \mathrm{AMPH}(2 \mathrm{mg} / \mathrm{kg})$ at 24,26 , and $42 \mathrm{hr}$ after L-dopa (filled arrowheads), and a control injection of PBS $44 \mathrm{hr}$ after L-dopa (open arrowhead). The black bars indicate when room lights were off. The increased activity at $30 \mathrm{hr}$ after L-dopa (white bar) is characteristic of DD mice (see Results). $B$, WT mice $(n=3)$ were treated as described for DD mice. C, Cumulative ambulations of WT (white columns) and DD (black columns) mice for $1.75 \mathrm{hr}$ after AMPH or PBS at 24 (AMPH 1), 26 (AMPH 2), 42 (AMPH 3), and 44 (PBS 1) hr after L-dopa. * $p<0.05$ compared with PBS value. D, DD and WT mice were given access to sucrose and water for $15 \mathrm{hr}$ beginning $28 \mathrm{hr}$ after the administration of $\mathrm{L}$-dopa, either after AMPH at 24 and $26 \mathrm{hr}$ (AMPH) or without previous AMPH administration (no AMPH). There was no difference in the total intake of DD or WT mice with or without previous AMPH administration.

$3 F)$. When normal animals drink sucrose, larger bout size, longer bout length, and increased lick rate indicate increased reward value (Davis and Smith, 1988; Smith, 1995; Smith and Sclafani, 2002). However, the number of bouts and total licks by DD mice were less than those of WT mice (Figs. $2 D, 3 B, C$ ). DD mice most often drank in abnormal, and apparently uncomfortable, postures. It appeared as if they had difficulty assuming a normal drinking position, and would begin to consume eagerly before they were able to assume a more comfortable position.

DD mice also preferred saccharin to water ( $>90 \%$ preference for saccharin by both DD and WT). Saccharin, like sucrose, elicited greater licks per bout in DD mice ( $144 \pm 53$ vs $33 \pm 4$ ). This suggests that caloric value is not required for preference in the absence of DA. However, neither DD nor WT mice licked as rapidly for saccharin as for sucrose ( $p<0.05$; data not shown), although both sweets were given at a concentration that elicits maximal lick rate (Bachmanov et al., 2001; Smith and Sclafani, 2002). This is consistent with previous results (Smith and Sclafani, 2002), which suggest that saccharin is not as palatable as sucrose.

\section{Juvenile DD mice demonstrate sucrose preference}

To address the possibility that previous experience with mother's milk or a rodent lab diet in the presence of DA is required for subsequent preference, we tested juvenile DD mice before their first injection of L-dopa. Naive, juvenile DD mice that had never been injected with $\mathrm{L}$-dopa demonstrate robust sucrose preference (Fig. 4).

\section{Discussion}

Brain reward processes probably evolved in response to natural rewards, such as the presence of food. The sweet taste of sucrose can condition a place preference (White and Carr, 1985), motivate operant responding (e.g., bar pressing) (Bailey et al., 1986), and elicit orofacial reactions suggestive of pleasure in animals (Grill and Norgren, 1978) and human infants (Steiner, 1973). The more concentrated the sucrose, the more rewarding it seems to be (Smith and Sclafani, 2002). For example, when animals press a bar to receive sucrose, they will work harder for concentrated sucrose than for dilute solutions (Bailey et al., 1986; Reilly, 1999). Likewise, lick rate increases as the sucrose concentration increases (Davis and Smith, 1988). In the present studies, DD mice demonstrated preference for sucrose and saccharin, as well as larger bout size, longer bout length, increased lick rate, and increased total consumption in response to sucrose and saccharin compared with water. We conclude that mice lacking DA find the sweet tastes of sucrose and saccharin rewarding.

Even simple behaviors motivated by reward, such as returning to a palatable food, also involve nonreward processes, e.g., sensory perception, motor ability, learning, and memory. In these studies, when WT mice found the palatable food, they returned to it often and preferentially. In contrast, the DD mice did not demonstrate an increased bout number in response to either sucrose or saccharin, and the total intake of sucrose and saccharin by DD mice was less than that of WT mice. Thus, in the absence of DA, DD mice exhibit profound constraints on performance during 


\section{A}

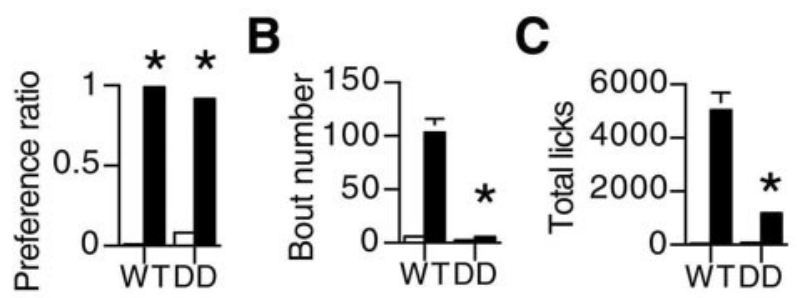

D
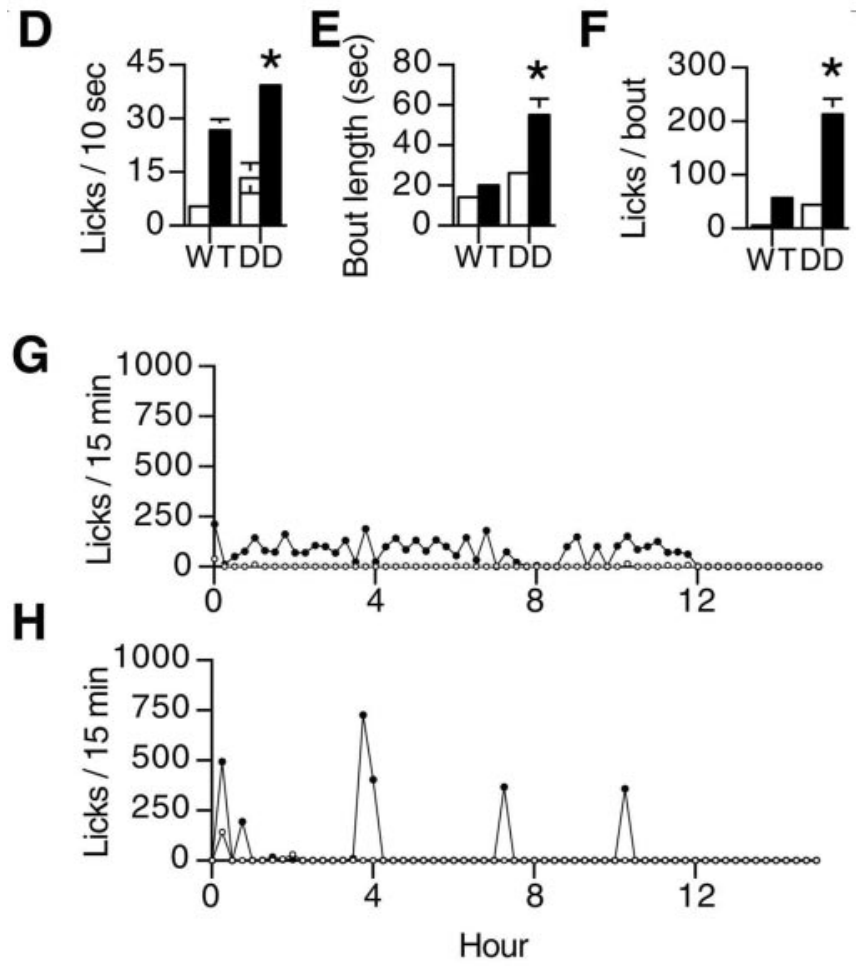

Figure 3. In the absence of releasable DA, DD mice preferred sweet solutions to water. WT $(n=7)$ and $\mathrm{DD}(n=8)$ mice were given the choice of sucrose (black columns) or water (white columns). $A$, Both groups demonstrated significant preference for sucrose $(p<0.01) . B, C, D D$ mice had fewer bouts (licking during consecutive 10 sec intervals) and fewer total licks at the sucrose tube compared with WT mice $(p<0.05)$. D-F, During each bout of sucrose intake, lick rate, bout length, and total licks/bout were greater for DD compared with WT mice $(p<0.01)$. $G, H$, Licking pattern of representative individual WT $(G)$ or DD $(H)$ mice given the choice of sucrose (filled circles) and water (open circles).

the sucrose preference task. Because DD mice can apparently taste sweets and have the motor ability to lick and move about the cage, gross sensory and motor deficits cannot explain the failure of DD mice to return to the reward more often, or to consume as much as the WT mice. We propose that the abnormalities demonstrated by DD mice during the sucrose preference test reveal a deficit in goal-directed behavior toward the sucrose reward. This deficit is also revealed by behaviors not required for sucrose preference [e.g., without L-dopa DD mice do not engage in reproductive behavior (Szczypka et al., 1998) or build a nest when bedding material is provided (Szczypka et al., 2001)]. They will starve to death when palatable solid or liquid food is readily available, unless they are injected daily with L-dopa or given food directly into the mouth. On the other hand, DD mice behave as if they are motivated to consume calories; when a liquid diet is delivered directly into the mouth via an intraoral cannula, they avidly consume it, and they can be maintained this way for many days in the absence of L-dopa (our unpublished observations). Although food is a reward, starvation is undoubtedly aversive (Bechara and van der Kooy, 1992). Yet DD mice do not eat enough to avoid
A

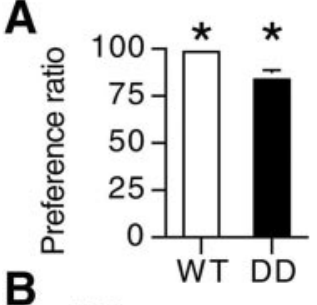

B

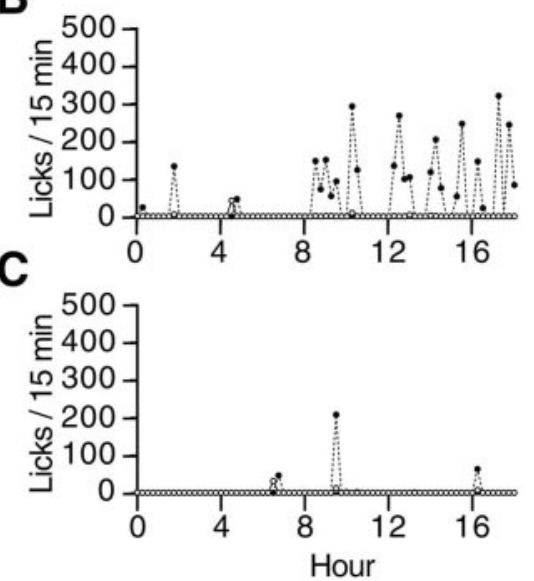

Figure 4. Previous experience with DA was not required for sucrose preference by DD mice. Juvenile DD $(n=4)$ and WT littermates $(n=4)$ were given the choice of sucrose or water before their first injection of $\mathrm{L}$-dopa. $A$, Both WT and DD juvenile mice preferred sucrose $(p<0.01) . B$, $C$, Licking pattern of representative individual WT $(B)$ or DD ( $C$ mice given the choice of sucrose (filled circles) or water (open circles). Juvenile DD mice demonstrated fewer total licks during the $18 \mathrm{hr}$ test (mean total licks: WT, $2667 \pm 855 ; \mathrm{DD}, 438 \pm 162$ ).

starvation, either to obtain food reward or to alleviate this aversive state. We propose that DA is necessary for goal-directed behaviors, feeding being just one physiologically important example.

The observations that DA is released in the striatum in response to natural and drug rewards (Hernandez and Hoebel, 1988; Hajnal and Norgren, 2001, 2002), that animals will work to elicit electrical stimulation of dopaminergic neurons (Wise, 2002), and that animals will self-administer many different classes of drugs that all enhance DA release (White, 2002) are consistent with the hypothesis that DA mediates the hedonic or pleasurable experience of rewards (Wise, 1994). Although this hypothesis was an important impetus to research in this area, it has been vigorous challenged (Salamone et al., 1997; Berridge and Robinson, 1998) and is giving way to alternative views that are more in line with our data. For example, the activity of dopaminergic neurons increases not only in response to rewarding stimuli but also in response to aversive stimuli such as a bitter quinine solution or even an electric shock (Horvitz, 2002). Thus, it may be more appropriate to think of dopaminergic activation as a consequence of unexpected environmental events rather than reward. Furthermore, increased firing of dopaminergic neurons does not necessarily equate with increased DA release in the striatum. For example, Garris et al. (1999) demonstrate that DA release in the nucleus accumbens could be detected during experimenter-delivered electrical stimulation of the midbrain dopaminergic neurons, but not when the animal was delivering the same stimulation to itself. Hence, release of DA in the nucleus accumbens is not necessary to sustain self-stimulation. Likewise, our experiments suggest that the preferential consumption of a sweet solution once it is discovered, whether it is nutritious or not, does not depend on DA release from dopaminergic neurons. 
Lastly, severe depletion of dopaminergic terminals in the striatum by the neurotoxin 6-OHDA ( $~ 99 \%$ depletion of DA) results in profound hypoactivity and anorexia; however, this treatment did not diminish the pleasurable facial expressions (taste reactivity) to intraorally infused sucrose (Berridge et al., 1989; Berridge and Robinson, 1998). These results suggest that DA is not required for the hedonic response to natural rewards. We suggest, instead, that the failure of DD mice to initiate feeding bouts reflects a generalized deficit of goal-directed behaviors that may be independent of reward processes. The fact that DD mice are able to orchestrate some complex behaviors (e.g., locomotion, grooming, climbing, and ingestion), suggests that DA facilitates goal-directed behaviors, but that other neurotransmitters are sufficient for their execution. We also suggest that DA release in the dorsal striatum is important for goal-directed behaviors, because viral restoration of DA signaling in that brain region of DD mice restores feeding, nest-building, and reproduction (Szczypka et al., 2001).

Drugs of abuse and natural rewards may act through the same brain reward circuits, and it is widely held that addiction occurs when drugs co-opt the reward processes naturally elicited by food, for example. DA may be critical to the development of addiction or to learning about the environmental events that predict reward (Robinson and Berridge, 2000; Nestler, 2002; Schultz, 2002). Here, we report that increased consumption of sweet solutions occurs even in naive juvenile DD mice that have never consumed food in the presence of DA. Thus, DA is not required for mice to learn to consume sweet solutions preferentially. However, we were unable to ascertain whether DD mice craved sucrose before they initiated drinking, or whether they learned and remembered which tube contained sucrose. More discrete behavioral tests, along with restoration of DA signaling to specific brain regions of these mice, should help refine the precise role of DA in learning about rewards and craving them, as in addiction.

\section{References}

Bachmanov AA, Tordoff MG, Beauchamp GK (2001) Sweetener preference of C57BL/6ByJ and 129P3/J mice. Chem Senses 26:905-913.

Bailey CS, Hsiao S, King JE (1986) Hedonic reactivity to sucrose in rats: modification by pimozide. Physiol Behav 38:447-452.

Bechara A, van der Kooy D (1992) A single brain stem substrate mediates the motivational effects of both opiates and food in nondeprived rats but not in deprived rats. Behav Neurosci 106:351-363.

Berridge KC, Robinson TE (1998) What is the role of dopamine in reward: hedonic impact, reward learning, or incentive salience? Brain Res Brain Res Rev 28:309-369.

Berridge KC, Venier IL, Robinson TE (1989) Taste reactivity analysis of 6-hydroxydopamine-induced aphagia: implications for arousal and anhedonia hypotheses of dopamine function. Behav Neurosci 103:36-45.

Davis J (1998) Measuring satiety: from meal size to the microstructure of ingestive behavior. In: Satiation: from gut to brain (Smith G, ed), pp 71-96. New York: Oxford UP.

Davis JD, Smith GP (1988) Analysis of lick rate measures the positive and negative feedback effects of carbohydrates on eating. Appetite 11:229-238.

Garris PA, Kilpatrick M, Bunin MA, Michael D, Walker QD, Wightman RM (1999) Dissociation of dopamine release in the nucleus accumbens from intracranial self-stimulation. Nature 398:67-69.

Grill HJ, Norgren R (1978) The taste reactivity test. I. Mimetic responses to gustatory stimuli in neurologically normal rats. Brain Res 143:263-279.

Hajnal A, Norgren R (2001) Accumbens dopamine mechanisms in sucrose intake. Brain Res 904:76-84.

Hajnal A, Norgren R (2002) Repeated access to sucrose augments dopamine turnover in the nucleus accumbens. NeuroReport 13:2213-2216.
Hall W, Bryan T (1980) The ontogeny of feeding in rats. II. Independent ingestive behavior. J Comp Physiol Psychol 94:746-756.

Hernandez L, Hoebel BG (1988) Food reward and cocaine increase extracellular dopamine in the nucleus accumbens as measured by microdialysis. Life Sci 42:1705-1712.

Heusner CL, Hnasko TS, Szczypka MS, Liu Y, During MJ, Palmiter RD (2003) Viral restoration of dopamine to the nucleus accumbens is sufficient to induce a locomotor response to amphetamine. Brain Res 980:266-274

Horvitz JC (2002) Dopamine gating of glutamatergic sensorimotor and incentive motivational input signals to the striatum. Behav Brain Res 137:65-74.

Kim DS, Szczypka MS, Palmiter RD (2000) Dopamine-deficient mice are hypersensitive to dopamine receptor agonists. J Neurosci 20:4405-4413.

Laakso A, Mohn A, Gainetdinov R, Caron M (2002) Experimental genetic approached to addiction. Neuron 36:213-228.

Nestler EJ (2002) From neurobiology to treatment: progress against addiction. Nat Neurosci [Suppl] 5:1076-1079.

Pecina S, Berridge KC, Parker LA (1997) Pimozide does not shift palatability: separation of anhedonia from sensorimotor suppression by taste reactivity. Pharmacol Biochem Behav 58:801-811.

Reilly S (1999) Reinforcement value of gustatory stimuli determined by progressive ratio performance. Pharmacol Biochem Behav 63:301-311.

Rios M, Habecker B, Sasaoko T, Eisenhofer G, Tian H, Landis S, Chikaraishi D, Roffler-Tarlov S (1999) Catecholamine synthesis is mediated by tyrosinase in the absence of tyrosine hydroxylase. J Neurosci 19:3519-3526.

Robinson TE, Berridge KC (2000) The psychology and neurobiology of addiction: an incentive-sensitization view. Addiction 95 [Suppl 2]:S91-S117.

Salamone J, Cousins M, Snyder B (1997) Behavioral functions of nucleus accumbens dopamine: empirical and conceptual problems with the anhedonia hypothesis. Neurosci Biobehav Rev 21:341-359.

Salamone JD, Correa M, Mingote S, Weber SM (2003) Nucleus accumbens dopamine and the regulation of effort in food-seeking behavior: implications for studies of natural motivation, psychiatry, and drug abuse. J Pharmacol Exp Ther 305:1-8.

Schultz W (2002) Getting formal with dopamine and reward. Neuron 36:241-263.

Smith G (1995) Dopamine and food reward. In: Progress in psychobiology and physiological psychology (Fluharty S, Morrison A, Sprague J, Stellar E, eds), pp 83-144. New York: Academic.

Smith JC, Sclafani A (2002) Saccharin as a sugar surrogate revisited. Appetite 38:155-160.

Steiner JE (1973) The gustofacial response: observation on normal and anencephalic newborn infants. Symp Oral Sens Percept 254-278.

Sulzer D, Chen TK, Lau YY, Kristensen H, Rayport S, Ewing A (1995) Amphetamine redistributes dopamine from synaptic vesicles to the cytosol and promotes reverse transport. J Neurosci 15:4102-4108.

Szczypka MS, Zhou QY, Palmiter RD (1998) Dopamine-stimulated sexual behavior is testosterone dependent in mice. Behav Neurosci 112:1229-1235.

Szczypka MS, Rainey MA, Kim DS, Alaynick WA, Marck BT, Matsumoto AM, Palmiter RD (1999) Feeding behavior in dopamine-deficient mice. Proc Natl Acad Sci USA 96:12138-12143.

Szczypka MS, Kwok K, Brot MD, Marck BT, Matsumoto AM, Donahue BA, Palmiter RD (2001) Dopamine production in the caudate putamen restores feeding in dopamine-deficient mice. Neuron 30:819-828.

Thomas SA, Marck BT, Palmiter RD, Matsumoto AM (1998) Restoration of norepinephrine and reversal of phenotypes in mice lacking dopamine beta-hydroxylase. J Neurochem 70:2468-2476.

White FJ (2002) A behavioral/systems approach to the neuroscience of drug addiction. J Neurosci 22:3303-3305.

White NM, Carr GD (1985) The conditioned place preference is affected by two independent reinforcement processes. Pharmacol Biochem Behav 23:37-42.

Wise R (1994) A brief history of the anhedonia hypothesis. In: Appetite: neural and behavioural bases (Legg C, Booth D, eds), pp 243-263. New York: Oxford UP.

Wise RA (2002) Brain reward circuitry: insights from unsensed incentives. Neuron 36:229-240.

Zhou QY, Palmiter RD (1995) Dopamine-deficient mice are severely hypoactive, adipsic, and aphagic. Cell 83:1197-1209. 